\title{
ARCHAEOLOGICAL COMPLEXES FROM CATACOMB OF SOUTH KAZAKHSTAN IN THE CONTEXT OF SARMATIAN THEMES
}

\author{
Alexandr N. Podushkin \\ South Kazakhstan State Pedagogical University, Shymkent, Republic of Kazakhstan
}

\begin{abstract}
The article is devoted to archaeological research of new discovered burial structures in the form of catacomb at the Kylyshzhar cemetery $\left(1^{\text {st }}\right.$ century $\mathrm{BC}-3^{\text {rd }}$ century $\left.\mathrm{AD}\right)$, in which artifacts were found similar to the monuments of the Sarmatian appearance. They include a number of ritual actions and burial implements close to the burial practice of the Sarmatians: range and blade weapons (iron tang daggers with a stone pommel, arrowheads), horse tack (iron girth buckles), bronze mirrors, household items and ritual objects (iron buckles, chalk amulets), jewelry (Egyptian faience ribbed beads). The characteristics of the grave goods from the catacombs of the Kylyshzhar cemetery, chronological calculations and ethno cultural interpretations indicate partial similarity between mentioned burials and the Sarmatian monuments of the $1^{\text {st }}$ century BC $-3^{\text {rd }}$ century AD despite major differences in such significant details of the funeral rite as the construction of burial pits and the orientation of the buried ones.

Key words: South Kazakhstan, catacomb archaeological monuments, Sarmatian similarities, Sarmatians, Kangyui, grave goods.

Citation. Podushkin A.N., 2021. Arheologicheskie kompleksy iz katakomb Yuzhnogo Kazahstana v kontekste sarmatskoy tematiki [Archaeological Complexes from Catacomb of South Kazakhstan in the Context of Sarmatian Themes]. Nizhnevolzhskiy Arkheologicheskiy Vestnik [The Lower Volga Archaeological Bulletin], vol. 20, no. 1, pp. 263-271. DOI: https://doi.org/10.15688/nav.jvolsu.2021.1.13
\end{abstract}

\section{АРХЕОЛОГИЧЕСКИЕ КОМПЛЕКСЫ ИЗ КАТАКОМБ ЮЖНОГО КАЗАХСТАНА В КОНТЕКСТЕ САРМАТСКОЙ ТЕМАТИКИ}

\section{Александр Николаевич Подушкин}

Южно-Казахстанский государственный педагогический университет, г. Шымкент, Республика Казахстан

Аннотация. Публикация посвящена археологическим исследованиям новых катакомбных погребений могильника Кылышжар (І в. до н.э. - III в. н.э.), в которых найдены артефакты, обнаруживающие сходство с памятниками сарматского культурного облика. Они включают близкий для погребальной практики сарматов перечень обрядовых действий и погребального инвентаря: дистанционное и клинковое оружие (железные черешковые кинжалы с каменным навершием, наконечники стрел), конскую атрибуцию (железные подпружные пряжки), бронзовые зеркала, бытовые и ритуальные предметы (железные пряжки, амулеты из мела), украшения (ребристые бусы из египетского фаянса). Характеристики погребальных артефактов из катакомб могильника Кылышжар, хронологические выкладки и этнокультурные интерпретации свидетель-

공 ствуют об их частичном сходстве с сарматскими памятниками І в. до н.э. - III в. н.э. при наличии существенণิ ных различий в таких значимых деталях погребального обряда, как конструкция погребальных ям и ориентигі ровка погребенных.

Ключевые слова: Южный Казахстан, катакомбные памятники, сарматские аналогии, Кангюй, погребальный инвентарь.

Цитирование. Подушкин А. Н., 2021. Археологические комплексы из катакомб Южного Казахстана в контексте сарматской тематики // Нижневолжский археологический вестник. Т. 20, № 1. С. 263-271. DOI: https://doi.org/10.15688/nav.jvolsu.2021.1.13 
Археологический отряд Южно-Казахстанского государственного педагогического университета продолжил исследование югозападной группы курганов могильника Кылышжар. Эта группа зафиксирована в 2 км к юго-западу от городища Культобе, в непосредственной близости от обрыва правого берега реки Арысь, на лессовой надпойменной террасе, которая в этом участке плавно спускается к руслу реки (Республика Казахстан, Туркестанская область, Ордабасинский район, в 2,2 км к северо-западу от с. Сарыарык; бывший пос. Социализм) (рис. 1). Насыпи курганов по отношению друг к другу расположены бессистемно. Они находятся на площадке размерами $200 \times 370$ м, ограниченной с восточной и западной сторон размытыми оврагами (отдельные группы насыпей располагались цепочками).

В целом юго-западная группа курганов могильника Кылышжар включает около 30 насыпей различных размеров и форм: встречены каплевидные в плане со смещенным центром; наиболее крутой склон, как правило, северный, реже - восточный. Имеются также округлые, слабовыраженные в рельефе насыпи. Все насыпи однородные по составу - они сложены из лесса. Средние размеры курганов могильника Кылышжар: диаметр от 8-10 до 30 и более метров при высоте от 0,8 до 2,5 м (рис. 1).

Курган 2 (рис. 1). В центре под насыпью, со смещением в западный сектор, на глубине 3,5 м от уровня дневной поверхности была обнаружена Т-образная трехчастная катакомба, которая включает узкотраншейный бесступенчатый дромос, аркообразный в разрезе лаз, связывающий дромос с погребальной камерой (проем лаза в древности был заложен прямоугольным кирпичом-сырцом) и сводчатую полую погребальную камеру овально-прямоугольной планировки.

Вся конструкция катакомбы вытянута по линии С-Ю, на дне камеры открыто одиночное погребение, основательно потревоженное древними грабителями: разрушенные останки костяка и погребального инвентаря в беспорядке располагались на полу у восточной стенки камеры (рис. 2,I). Обряд погребения (предположительно) - трупоположение на спине. В числе иных особенностей обряда отме- тим факт фиксации фрагментов дерева и угля, а также наличие костей овцы.

Погребальный инвентарь представлен следующими артефактами:

- кувшин столовый керамический грушевидной формы с выраженной горловиной, без ручек, декорирован красно-коричневым ангобом, поверх которого в нижней части сосуда, начиная от плечиков, нанесен черный ангоб и брызги насыщенного темного ангоба (рис. 2,1);

- часть крупного кухонного грушевидного горшка без ручек (форма восстанавливается; внешняя поверхность носит следы использования на открытом огне) (рис. 2,2);

- железные черешковые трехлопастные наконечники стрел нескольких видов: с опущенными и прямыми жальцами (4 экз.; рис. 2,3-5);

- железный двулопастной вильчатый наконечник стрелы (рис. 2,6); на черешках всех наконечников отмечены следы от деревянных древков;

- железный черешок кинжала (рис. 2,9), круглое каменное навершие от него с отверстием в центре (рис. 2,10), две железные скобы (рис. $2,14,16$ ) и железный обломок черешка ножа (рис. 2,7);

- железный нож (рис. 2,8);

- крупная круглая железная пряжка с подвижным язычком (рис. 2,12), две прямоугольные железные пряжки с подвижным язычком (рис. $2,13,15$ ) и круглая железная пряжка без язычка (рис. 2,11);

- часть железной втулки с остатками дерева от ножен кинжала (рис. 2,18 ) и часть бронзовой декоративной пластины со шляпками от заклепки (рис. 2,20);

- крупная ребристая бусина из египетского фаянса (рис. 2,17 ) и небольшой меловой амулет (рис. 2,19).

Курган 8 (рис. 1). Насыпь по форме каплевидная, диаметр 10 м, высота 0,6 м, сложена из лесса. Северный склон имеет большую крутизну, нежели южный. В юго-западном секторе насыпи, у ее кромки, на глубине 2,7 м от уровня дневной поверхности была обнаружена погребальная конструкция в виде Т-образной двухчастной катакомбы (рис. 3,I), которая включает: траншейный одноступенчатый дромос; проем аркообразного вида, свя- 
зывающий дромос с погребальной камерой (входное устье лаза заложено горизонтальными рядами кладки из прямоугольного кирпича-сырца); сводчатую полую погребальную камеру неправильной трапециевидной планировки (рис. $3, I$ ).

Вся конструкция вытянута по линии северо-восток - юго-запад, дромос примыкает к камере под прямым углом. Катакомба была частично потревожена в древности, о чем свидетельствует сдвинутый со своих мест погребальный инвентарь и разбитый алебастровый амулет. На дне погребальной камеры, у ее северной стенки, обнаружено одиночное погребение женщины средних лет. Обряд погребения - трупоположение на спине с ориентацией изголовья на восток (рис. $3, I$ ). В числе обрядовых особенностей:

- наличие костей овцы, в том числе лопатки, которые располагались на дне погребальной камеры между кувшином и горшком (рис. 3, I,9);

- обгоревшие остатки органического материала на внутренней стороне донца фрагментированного кухонного сосуда (следствие обрядовых действий, связанных с культом огня) (рис. 3,3).

Погребальный инвентарь включает:

1. Столовый керамический кувшин грушевидной формы без ручек. Верхняя часть тулова, горловина и венчик до плечика сосуда покрыты красно-коричневым ангобом с использованием ангобных потеков темно-коричневого, почти черного цвета; нижняя часть тулова покрыта светло-коричневым ангобом с белесым оттенком, на которой также фиксируются ангобные потеки темного цвета (рис. 3,1 ).

2. Горшок керамический кухонный грушевидной формы без горловины и ручек (венчик и тулово изделия деформированы). Декор у горшка отсутствует. Внешняя поверхность закопчена (рис. 3,2).

3. Фрагмент донца и нижней части лепного кухонного горшка (форма не восстанавливается) (рис. 3,3).

4. Зеркало бронзовое дисковидное с боковой ручкой, невысоким конусовидным выступом в центре оборотной плоскости диска и слабовыраженным валиком по периметру диска (рис. 3,5).
5. Нож железный черешковый бытовой со следами деревянной ручки на штыре (рис. 3,4).

6. Амулет алебастровый овально-прямоугольный в разрезе с округлым окончанием. Одна сторона уплощена, на другой - следы функционально-ритуального использования (рис. 3,8).

7. Железную пряжку прямоугольной формы с остатками дерева на соединительных штырях, круглых в разрезе (рис. 3,7).

8. Декоративную бронзовую пластину прямоугольной формы с клепками-фиксаторами на венчик деревянного сосуда (рис. 3,6).

Инвентарь в погребении располагался следующим образом. Железный нож был вложен в левую кисть руки покойной. От изголовья костяка последовательно, цепочкой с севера на юг, на дно камеры были положены бронзовое зеркало, алебастровый амулет, кухонный миниатюрный горшок, кости овцы, столовый кувшин и часть донца кухонного горшка с остатками сгоревшей органики (рис. $3, I$ ).

Остановимся на некоторых аналогиях и параллелях археологическому материалу и обряду погребения из катакомб могильников Кылышжар. В качестве уверенных хроноиндикаторов выступают несколько артефактов, дающих основание для соответствующих выводов.

Керамика местного производства (кувшины столовые) из катакомб могильника Кылышжар иллюстрирует как классические формы, декор и назначение посуды арысской культуры Южного Казахстана I в. до н.э. - IV в. н.э. [Подушкин, 2000, с. 132-135], так и принадлежность к импортным керамическим изделиям (кухонные горшки), широко известным в памятниках европейской и Азиатской Сарматии первых веков до н.э. - первых веков н.э. [Мошкова, 1989a, с. 181 , табл. 74,8,10,14-16,23-24, $75,10,12,22,28$; Скрипкин, 1984, с. 24-32, рис. 4,$4 ; 5,9,7,11,14,8,2,4$; Скрипкин, 1990 , c. $37-42$, pис. $8,1,7,13,16,20-21,9,14-15,18-$ $20,26,28,32,34]$. При этом некоторые параллели уводят к поселенческим материалам юго-западной Ферганы первых веков н.э. [Брыкина, 1982, с. 66, табл. 22,2; Литвинский, 1973, с. 103, табл. 2, 3] и материалам могильников Западного Памира [Литвинский, 1973, с. 100 , табл. 43,9]. 
В качестве датирующего материала из катакомб Южного Казахстана выступают железные черешковые наконечники стрел с «опущенными» и прямыми жальцами, которые широко встречаются в погребальных памятниках сарматов последних веков до н.э. III в. н.э. [Хазанов, 1971, с. 39, табл. ХХ,2021, табл. XXI,22,24; Скрипкин, 1990, с. 135141, рис. 24,33,35-36,54; Мошкова, 1989а, c. 185 , табл. $81,11,16,37,406$; Симоненко, 2010 , c. $96-99$, рис. $68,1,3$, рис. 69]. Подобные железные черешковые трехлопастные наконечники стрел находят аналогии и в среднеазиатских материалах последних веков до н.э. - первых веков н.э. [Литвинский, 1965, с. 77-81, рис. 4; Горбунова, 2000, с. 40-41, рис. 1,3,5,16, 2,1,4].

Железные мечи и кинжалы без перекрестия с каменными навершиями характерны для конца среднесарматской и всей позднесарматской культуры I-III вв. н.э. [Мошкова, 1989б, с. 195-197, табл. 81,59,60-61; Симоненко, 2010, с. 46, рис. 29-30, рис. 37]. Они зафиксированы в указанное время в погребальных памятниках Средней Азии [Обельченко, 1972, с. 57-62, рис. 1; Обельченко, 1973, с. 159171; Обельченко, 1978, с. 119-121], Средней Сырдарьи [Максимова и др., 1968, с. 184, рис. 3, табл. IV,1,3].

Бронзовые дисковидные зеркала с боковой ручкой, бортиком по краю и конусовидным выступом в центре декоративной поверхности характерны для погребений среднесарматской культуры последних веков до II в. н.э. [Мошкова 1989a, с. 187-188; Скрипкин, 2017, c. 173]. К числу хроноиндикаторов следует отнести большую ребристую бусину из египетского фаянса. Подобные бусины в сочетании с другими изделиями из египетского фаянса в составе наборных ожерелий и ручных браслетов широко распространены в среде сарматов Евразии в I в. до н.э. - III в. н.э.
[Алексеева, 1975, с. 25; Алексеева, 1984, с. 237 ; Мошеева, 2010, с. 152; Литвинский, Седов, 1984, с. 64].

Амулеты из алебастра, мела (или куски из этих материалов) фиксируются на всей территории расселения сарматов как изделия, имеющие отношение к особым погребальным действиям: связь с культом огня (заменители последнего [Мошкова 1989a, с. 179]) и ритуалом сакрального «очищения» погребального сооружения [Медведев, 2008, с. 55]. Амулеты имели хождение в среднесарматское и позднесарматское время [Медведев 2008, с. 5556; Мошкова 1989б, с. 202, табл. 80).

Таким образом, железные черешковые кинжалы с каменным навершием, бронзовые зеркала с ручкой и конусовидным возвышением в центре диска, железные пряжки, железные черешковые трехлопастные наконечники стрел, алебастровые, меловые амулеты, ребристые бусы из египетского фаянса находят близкие параллели в сарматских археологических культурах, что может свидетельствовать о наличии этнокультурных связей между населением, оставившим могильник Кылышжар, и кочевниками Азиатской Сарматии.

В исследуемом могильнике фиксируются и специфические обрядовые действия, присущие сарматам, связанные с культом огня, сакральным очищением погребального сооружения, присутствием «жертвенной пищи» в погребении [Мошкова, 1989a, с. 179].

Проблема взаимоотношения населения государственного объединения Канцзюй (Кангюй) на территории Южного Казахстана и сарматов евразийских степей периодически находится в поле зрения исследователей, многие детали этих взаимоотношений являются дискуссионными. Появление новых данных археологических исследований позволит более полно осветить эту проблемную тему. 


\section{ИЛЛЮСТРАЦИИ}

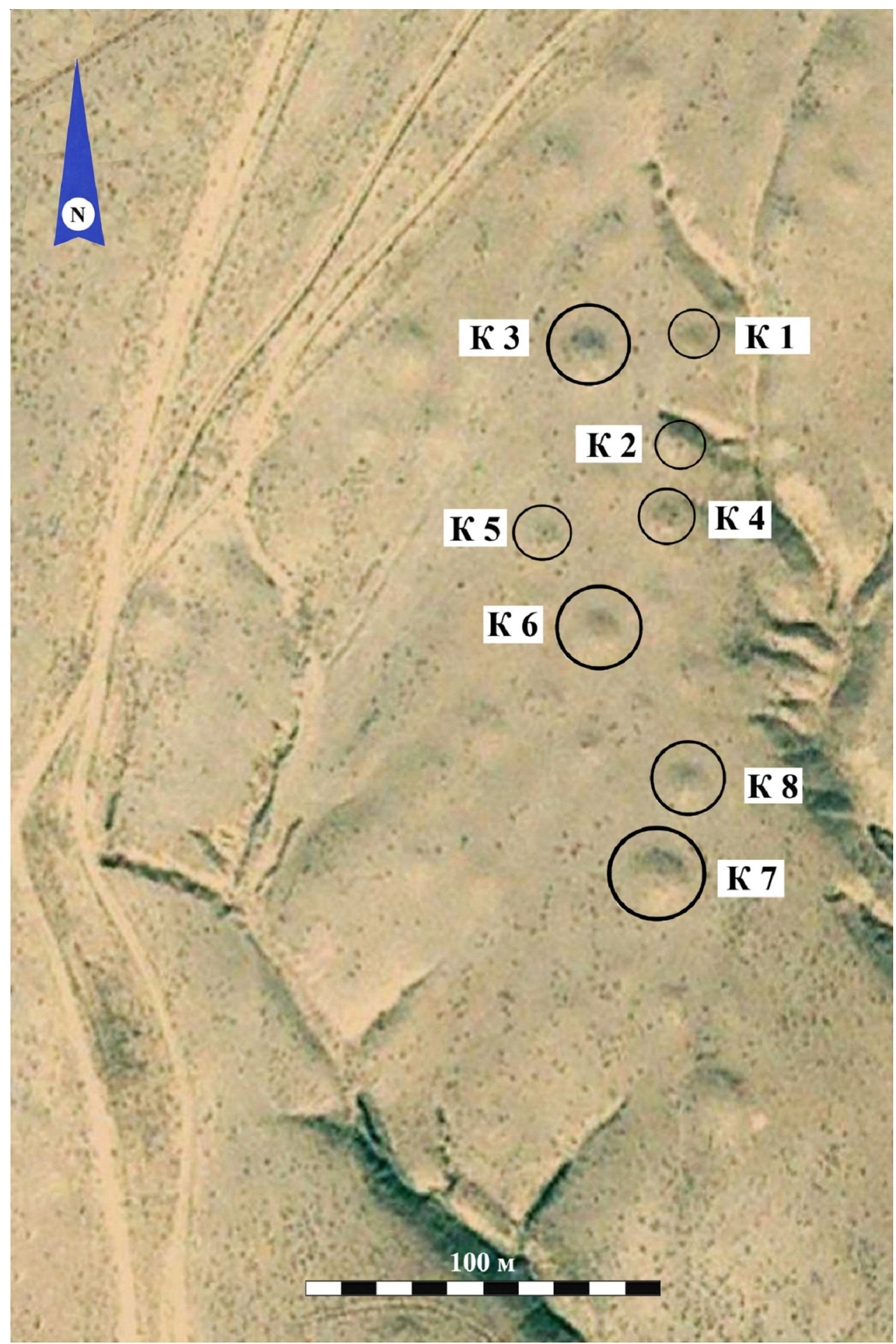

Рис. 1. Могильник Кылышжар, юго-западная группа курганов. Вид сверху, маркировка открытых насыпей

Fig. 1. Kylyshzhar cemetery, southwestern group of kurgans. Top view, marking of open embankments 

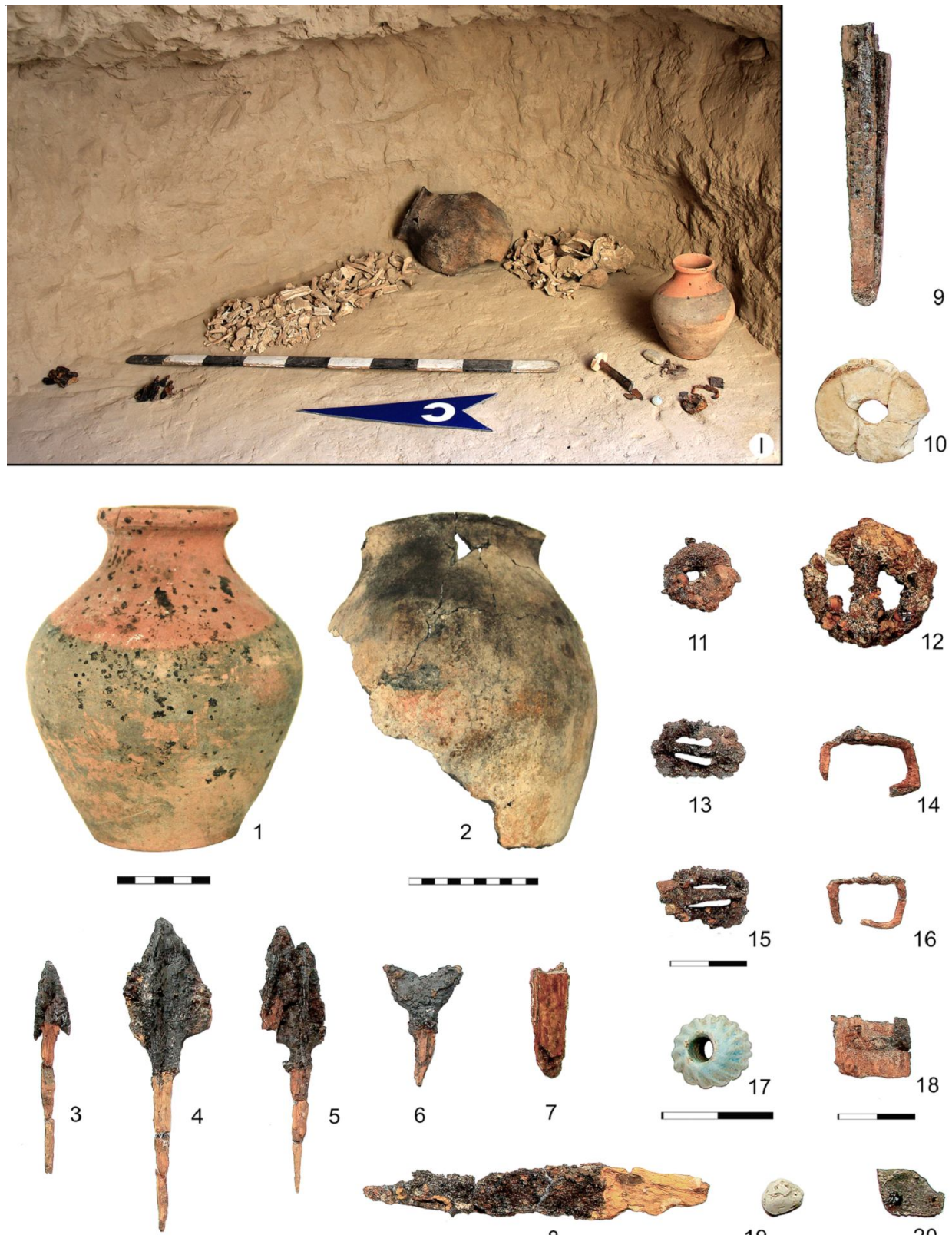

16

Рис. 2. Археологический комплекс кургана 2 юго-западной группы курганов могильника Кылышжар (фото авт.):

$I$ - часть полой погребальной камеры и основная масса артефактов; 1 - керамический столовый кувшин;

2 - часть кухонного горшка; 3-5 - железные черешковые трехлопастные наконечники стрел; 6 - железный вильчатый двулопастной наконечник стрелы; 7 - часть железного черешка от ножа; 8 - железный черешковый нож;

9 - железный черешок кинжала; 10 - каменное навершие от железного кинжала; 11 - круглая железная пряжка без язычка; 12 - крупная круглая железная пряжка с подвижным язычком, атрибут конской экипировки; 13, 15 - прямоугольные железные пряжки с подвижным язычком, атрибуты кожаной обуви; 14, 16 - железные скобы; 17 - ребристая бусина из египетского фаянса; 18 - часть железной втулки с остатками дерева, атрибут ножен кинжала; 19 - меловой амулет; 20 - часть бронзовой декоративной пластины со шляпками от заклепки

Fig. 2. Archaeological complex of kurgan 2 of the southwestern group of kurgans at the Kylyshzhar cemetery (photo by author):

$I$ - part of the hollow burial chamber and the bulk of the artifacts; 1 - ceramic table jug; 2 - part of a kitchen pot;

3-5 - iron petiolate three-bladed arrowheads; 6 - iron forked two-bladed arrowhead; 7 - part of the iron stem from the knife; 8 - iron petiole knife; 9 - iron stalk from a dagger; 10 - stone pommel from an iron dagger; 11 - round iron buckle without a tongue; 12 - large round iron buckle with a movable tongue, an attribute of horse equipment; 13,15 - rectangular iron buckles with a movable tongue, attributes of leather shoes; 14, 16 - iron staples; 17 - ribbed bead of Egyptian faience; 18 - part of an iron sleeve with the

remains of a tree, an attribute of a dagger sheath; 19 - chalk amulet; 20 - part of a bronze decorative plate with rivet caps 

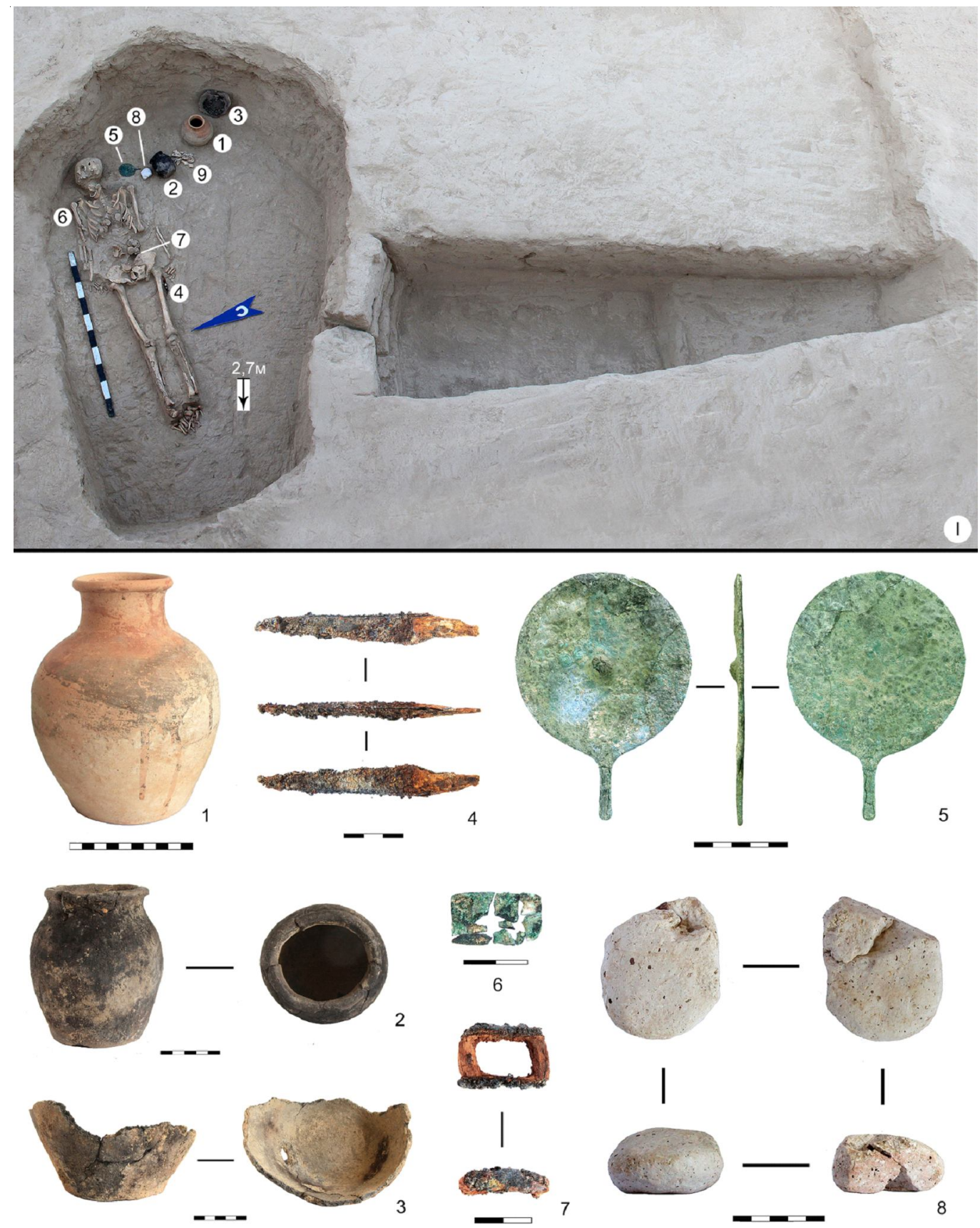

Рис. 3. Археологический комплекс кургана 8 юго-западной группы курганов могильника Кылышжар (фото авт.):

$I$ - погребение в катакомбе, вид сверху; 1 - кувшин керамический столовый; 2 - горшок керамический кухонный; 3 - фрагмент донца и нижней части кухонного горшка; 4 - нож железный черешковый; 5 - зеркало бронзовое дисковидное с боковой ручкой-штырем;

6 - декоративная бронзовая пластина прямоугольной формы с клепками-фиксаторами;

7 - железная пряжка прямоугольной формы с остатками дерева; 8 - амулет алебастровый

Fig. 3. Archaeological complex of kurgan 8 of the southwestern group of kurgans at the Kylyshzhar cemetery (photo by author):

$I$ - burial in the catacomb, top view; 1 - ceramic dining jug; 2 - ceramic kitchen pot; 3 - a fragment of the bottom and lower part of a kitchen pot; 4 - iron petiole knife;

5 - bronze disc-shaped mirror with a lateral handle-pin;

6 - decorative bronze rectangular plate with rivets-clamps;

7 - a rectangular iron buckle with the remains of a tree; 8 - alabaster amulet 


\section{СПИСОК ЛИТЕРАТУРЫ}

Алексеева Е. М., 1975. Античные бусы Северного Причерноморья. САИ. Вып. Г 1-12. М. : Наука. 105 с. Алексеева Е. М., 1984. Бусы и подвески // Археология СССР. Античные государства Северного Причерноморья. М. : Наука. С. 237-239.

Брыкина Г. А., 1982. Юго-Западная Фергана в первой половине I тысячелетия нашей эры. М. : Наука. 196 с.

Горбунова Н. Г., 2000. О вооружении среднеазиатских скотоводов (II (III?) в. до н.э. - V в. н.э.) // Российская археология. № 2. С. 40-51.

Литвинский Б. А., 1965. Среднеазиатские железные наконечники стрел // Советская археология. № 2. С. 75-91.

Литвинский Б. А., 1973. Керамика из могильников Западной Ферганы. М. : Наука. 202 с.

Литвинский Б. А., Седов А. В., 1984. Культы и ритуалы Кушанской Бактрии. М. : Наука. 137 с.

Максимова А. Г., Мерщиев М. С., Вайнберг Б. И., Левина Л. М., 1968. Древности Чардары. Алма-Ата : Наука Казахской ССР. 258 c.

Медведев А. П., 2008. Сарматы в верховьях Танаиса. М. : Таус. 252 с.

Мошеева О. Н., 2010. Египетский фаянс в сарматских погребениях Нижнего Поволжья // Нижневолжский археологический вестник. Вып. 11. С. 147-169.

Мошкова М. Г., 1989а. Средне-сарматская культура // Археология СССР. Степи европейской части СССР в скифо-сарматское время. М. : Наука. С. 177-191.

Мошкова М. Г., 1989б. Поздне-сарматская культура // Археология СССР. Степи европейской части СССР в скифо-сарматское время. М. : Наука. С. 191-202.

Обельченко О. В., 1972. Агалыксайские курганы // История материальной культуры Узбекистана. Вып. 9. Ташкент : Изд-во АН Узбекской ССР. С. 56-72.

Обельченко О. В., 1973. Курганы в окрестностях Самарканда // Афрасиаб. Вып. ІІ. Ташкент : Изд-во АН Узбекской ССР. С. 157-172.

Обельченко О. В., 1978. Мечи и кинжалы из Согда // Советская Археология. № 4. С. 115-127.

Подушкин А. Н., 2000. Арысская культура Южного Казахстана IV в. до н. э. - VI в. н. э. Туркестан : МКТУ. 201 с. Симоненко А. В., 2010. Сарматские всадники Северного Причерноморья. СПб. : Факультет филологии и искусств СПбГУ ; Нестор-История. 328 с.

Скрипкин А. С., 1984. Нижнее Поволжье в первые века нашей эры. Саратов : Сарат. ун-т. 150 с.

Скрипкин А. С., 1990. Азиатская Сарматия. Проблемы хронологии и ее исторический аспект. Саратов : Изд-во Сарат. ун-та. 300 с.

Скрипкин А. С., 2017. Сарматы. Волгоград : Изд-во ВолГУ. 293 с.

Хазанов А. М., 1971. Очерки военного дела сарматов. М. : Наука. 172 с.

\section{REFERENCES}

Alekseeva E.M., 1975. Antichnyye busy Severnogo Prichernomor'ya [Antique Beads of the Northern Black Sea Region]. Svod arkheologicheskih istochnikov, iss. Г1-12. Moscow, Nauka Publ. 105 p.

Alekseeva E.M., 1984. Busy i podveski [Beads and pendants]. Arkheologiya SSSR. Antichnyye gosudarstva Severnogo Prichernomor'ya [Archeology of the USSR. Ancient States of the Northern Black Sea Region]. Moscow, Nauka Publ., pp. 237-239.

Brykina G.A., 1982. Yugo-Zapadnaya Fergana v pervoy polovine I tysyacheletiya nashey ery [South-West Fergana in the First Half of the $1^{\text {st }}$ Millennium AD]. Moscow, Nauka Publ. 196 p.

Gorbunova N.G., 2000. O vooruzhenii sredneaziatskikh skotovodov (II (III?) v. do n.e. - V v. n.e.) [The Weapons of Central Asiatic Cattle-Breaders (the $2^{\text {nd }}\left(3^{\text {rd }}\right.$ ?) Century B.C. - the $5^{\text {th }}$ Century A.D. $\left.)\right]$. Rossiyskaya arkheologiya [Russian Archaeology], no. 2, pp. 40-51.

Litvinskiy B.A., 1965. Sredneaziatskiye zheleznyye nakonechniki strel [Central Asian Iron Arrowheads]. Sovetskaya arkheologiya [Soviet Archaeology], no. 2, pp. 75-91.

Litvinskiy B.A., 1973. Keramika iz mogil'nikov Zapadnoy Fergany [Ceramics from the Cemeteries of Western Fergana]. Moscow, Nauka Publ. 202 p. 
Litvinskiy B.A., Sedov A.V., 1984. Kul'ty i ritualy Kushanskoy Baktrii [Cults and Rituals of Kushan Bactria]. Moscow, Nauka Publ. 137 p.

Maksimova A.G., Mershchiev M.S., Weinberg B.I., Levina L.M., 1968. Drevnosti Chardary [Antiquities of Chardara]. Alma-Ata, Nauka Kazahskoy SSR Publ. 258 p.

Medvedev A.P., 2008. Sarmaty v verkhov'yakh Tanaisa [Sarmatians in the Upper Reaches of the Tanais]. Moscow, Taus Publ. 252 p.

Mosheeva O.N., 2010. Yegipetskiy fayans v sarmatskikh pogrebeniyakh Nizhnego Povolzh'ya [Egyptian Faience in Sarmatian Burials of the Lower Volga Area]. Nizhnevolzhskiy Arkheologicheskiy Vestnik [The Lower Volga Archaeological Bulletin], iss. 11, pp. 147-169.

Moshkova M.G., 1989a. Sredne-sarmatskaya kul'tura [Middle Sarmatian Culture]. Arkheologiya SSSR. Stepi yevropeyskoy chasti SSSR v skifo-sarmatskoye vremya [Archaeology of the USSR. Steppes of the European part of the USSR in the Scythian-Sarmatian Time]. Moscow, Nauka Publ., pp. 177-191.

Moshkova M.G., 1989b. Pozdne-sarmatskaya kul'tura [Late Sarmatian Culture]. Arkheologiya SSSR. Stepi yevropeyskoy chasti SSSR v skifo-sarmatskoye vremya [Archeology of the USSR. Steppes of the European part of the USSR in the Scythian-Sarmatian Time]. Moscow, Nauka Publ., pp. 191-202.

Obelchenko O.V., 1972. Agalyksayskiye kurgany [Agalyksay Kurgans]. Istoriya material'noy kul'tury Uzbekistana [History of Material Culture of Uzbekistan], iss. 9. Tashkent, Academy of Sciences of the Uzbek SSR, pp. 56-72.

Obelchenko O.V., 1973. Kurgany v okrestnostyakh Samarkanda [Kurgans in the Vicinity of Samarkand]. Afrasiab [Afrasiab], iss. II. Tashkent, Academy of Sciences of the Uzbek SSR, pp. 157-172.

Obelchenko O.V., 1978. Mechi i kinzhaly iz Sogda [Swords and daggers from Sogd]. Sovetskaya arkheologiya [Soviet Archeology], no. 4, pp. 115-127.

Podushkin A.N., 2000. Arysskaya kul'tura Yuzhnogo Kazakhstana IVv. do n. e. - VIv. n. e. [Arys Culture of South Kazakhstan IV Century BC - VI Century AD]. Turkestan, A. Yassavi International Kazakh-Turkish University. $201 \mathrm{p}$.

Simonenko A.V., 2010. Sarmatskiye vsadniki Severnogo Prichernomor'ya [Sarmatian Riders of North Pontic Region]. Saint-Petersburg, St. Petersburg State University, Faculty of Philology and Arts; Nestor-History. 328 p.

Skripkin A.S., 1984. Nizhnee Povolzh'e v pervye veka nashey ery [The Lower Volga region in the first centuries of our era]. Saratov, SSU. 150 p.

Skripkin A.S., 1990. Aziatskaya Sarmatiya. Problemy hronologii i ee istoricheskiy aspekt [Asian Sarmatia. Problems of Chronology and its Historical Aspect]. Saratov, SSU. 300 p.

Skripkin A.S., 2017. Sarmaty [The Sarmatians]. Volgograd, VolSU. 293 p.

Khazanov A.M., 1971. Ocherki voyennogo dela sarmatov [Essays on the Military Affairs of the Sarmatians]. Moscow, Nauka Publ. 172 p.

\section{Information About the Author}

Alexandr N. Podushkin, Doctor of Sciences (History), Professor of the Department of History of Kazakhstan and the World, South Kazakhstan State Pedagogical University, Baitursynov St, 13, 160012 Shymkent, Republic of Kazakhstan, p_a_n_alex@mail.ru, https://orcid.org/0000-0003-1603-1373

\section{Информация об авторе}

Александр Николаевич Подушкин, доктор исторических наук, профессор кафедры истории Казахстана и мира, Южно-Казахстанский государственный педагогический университет, ул. Байтурсынова, 13, 160012 г. Шымкент, Республика Казахстан, p_a_n_alex@mail.ru, https://orcid.org/0000-0003-1603-1373 